Check for updates

Cite this: Inorg. Chem. Front., 2020, 7, 289

Received 3rd September 2019, Accepted 25th October 2019

DOI: 10.1039/c9qi01132c

rsc.li/frontiers-inorganic

\title{
Joining the journey to near infrared (NIR) imaging: the emerging role of lanthanides in the designing of molecular probes
}

\author{
Guo-Qing Jin, Yingying Ning, Jing-Xing Geng, Zhi-Fan Jiang, Yan Wang and \\ Jun-Long Zhang (iD *
}

Near-infrared (NIR, 700-1700 nm) bioimaging has gained considerable attention in recent years owing to its high imaging resolution and increasing penetration depth of tissues. NIR emissive lanthanide(III) complexes have emerged as alluring candidates for the design of NIR molecular probes in clinical imaging and diagnosis because of their desirable temporal-spatial resolution, negligible photobleaching effect, long lifetime and low biotoxicity. In this mini-review, we summarize our efforts in the molecular design of NIR luminescent lanthanide porphyrinoids and their biological applications in bioimaging and further clinical diagnosis and treatment. Remarkably, $\beta$-fluorinated porphyrin $\mathrm{Yb}^{3+}$ probes exhibit high luminescence (5-13\% quantum yields in $\mathrm{H}_{2} \mathrm{O}$ ), long decay lifetimes (>100 $\left.\mu \mathrm{s}\right)$ and enable in vivo fluorescence intensity imaging and time-resolved fluorescence lifetime imaging (FLIM). Finally, the main concerns and challenges for NIR emissive Ln biolabels such as the diversity of the NIR $\mathrm{Ln}^{3+}$ optical toolbox and their biocompatibility and targeting capability in biological media are discussed so as to facilitate the long-term development of lanthanide chemical biology.
\end{abstract}

\section{Introduction}

Near-infrared (NIR, 700-1700 $\mathrm{nm}$ ) fluorescence imaging has received considerable attention as an emerging tool in clinical diagnosis and therapy owing to its exceptional advantages such as deep tissue imaging with minimum auto-fluorescence interference and high signal-to-background ratios. ${ }^{1-10}$ Engineering, Peking University, Beijing 100871, P. R. China.

E-mail: zhangjunlong@pku.edu.cn; Fax:+86-10-62767034

Guo-Qing Jin received his B.S. degree from Soochow University in 2018. Now he is a Ph.D. student in Prof. Jun-Long Zhang's group. His research focuses on the design of NIR lanthanide molecular probes and porpholactone chemistry.

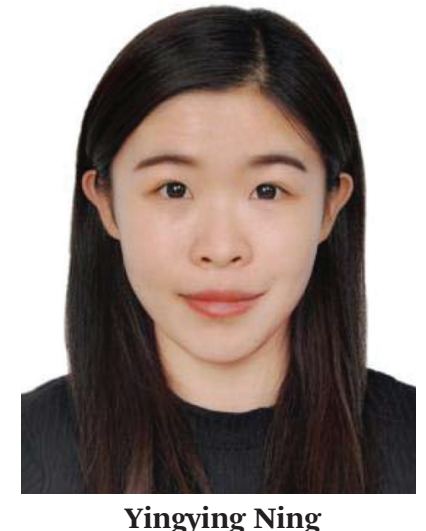

Yingying Ning received her two B.S. degrees in chemistry and statistics from Renmin University of China in 2014. In 2019, she received a Ph.D. degree in bioinorganic chemistry under the supervision of Prof. Jun-Long Zhang. She is currently a postdoctoral fellow at Massachusetts General Hospital and Harvard Medical School. During her Ph.D. study, she received several honors such as the National Scholarship for Graduate Students, Dow's Research Award for Graduate Students, etc. and her PhD thesis was selected for the award of "100 excellent doctoral thesis" in PKU. 
Development of NIR probes is essential to extend such an approach to clinical translation and, to date, various NIR probes have been reported including organic fluorophores, ${ }^{1}$ conjugated copolymers, ${ }^{11}$ quantum dots (QDs), ${ }^{12}$ single-walled carbon nanotubes (SWCNTS) ${ }^{13}$ and rare-earth-doped nanoparticles (RENPs). ${ }^{13,14}$ In spite of tremendous progress made in the last two decades, the lack of NIR fluorophores with both high quantum yield (QY) and good biocompatibility remains a dominant barrier. For example, small molecular organic fluorophores have considerable advantages such as synthetic flexibility, biocompatibility and biosafety benefited from the small sizes and sophisticated synthetic methodology; however, they suffer from easy photobleaching and low quantum yields. ${ }^{4,5,15}$ On the other hand, the nanomaterials such as SWCNTS, QDs and RENPS have fascinating photophysical properties, but the potential toxicity or/and metabolism issues, arising from metal ion release and the molecular size effect, hamper their further practical applications. ${ }^{5,7,16}$ Thus, exploring an alternative approach to construct NIR probes combining the merits of organic small molecules and metal nanoparticles is of importance.

To address these issues, we envisaged the utilization of lanthanide (Ln) coordination compounds, which feature metal-centered luminescence arising from the characteristic f-f transitions with good photostability, large Stokes shift, and long lifetime, and provide a toolkit box for NIR probes covering the deep red to NIR region (700-1700 nm). ${ }^{17-20}$ Since the forbidden nature of $\mathrm{Ln}^{3+} \mathrm{f}-\mathrm{f}$ transitions results in a low molar absorption coefficient, the crucial choice of the antenna ligand renders the direct excitation of the ligand with a large absorption section capable of achieving intense NIR luminescence. In view of molecular sizes and the related metabolism

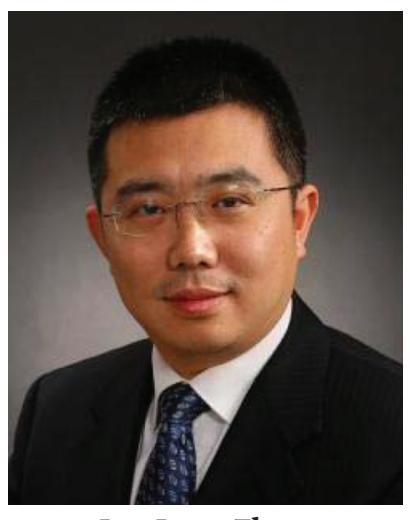

Jun-Long Zhang received his B.Sc. degree from Sichuan University (1997), M.Sc. degree from Chengdu Institute of Organic Chemistry, CAS (2000), and Ph.D. from the University of Hong Kong (supervisor: Prof. Chi-Ming Che, 2005). After postdoctoral research with Prof. Yi Lu in UIUC, he started his independent academic career in the College of Chemistry and Molecular Engineering, Peking University. Professor Zhang's research focuses on biomimetic tetrapyrrole cofactors, non-noble metal (including lanthanide) molecular probes, and their applications in multimodal imaging and therapy. He has received several awards such as the Europe Early Career Award by ChemPubSoc, Distinguished Lectureship Award by Chemical Society of Japan, and Emerging Investigator in Bioinorganic Chemistry by the ACS. mechanism, the coordination compounds are more like organic dyes than metal nanoparticles. Moreover, the synthetic flexibility of organic ligands provides access to biocompatible modifications with a well-defined approach. ${ }^{18,21}$ Thus, NIR emissive Ln complexes are anticipated to stand out as unique optical tags in the NIR toolkit box.

Thanks to the flourishing lanthanide coordination chemistry, various NIR Ln-based molecular probes have been prepared and further applied even in in vivo imaging. ${ }^{22-26}$ In spite of great progress made in recent years, the development of NIR lanthanide probes is still limited by the low quantum yields $(<5 \%)$ because the energy transfer efficiency is uncertain and the acceptor excited level of NIR $\mathrm{Ln}^{3+}$ cations is easily quenched by vibrational overtones of $\mathrm{X}-\mathrm{H}(\mathrm{X}=\mathrm{C}, \mathrm{H}, \mathrm{O})$ oscillators. ${ }^{21,27,28}$ Our group is interested in mimicking natural tetrapyrrole cofactors, some of which behave like a light harvesting antenna, and thus in developing an antenna ligand to sensitize Ln NIR emission exemplified by ytterbium $\left(\mathrm{Yb}^{3+}\right)$. Porpholactone shows strong UV-visible absorption and has a unique tetrapyrrolic coordination sphere and tunable triplet state $\left(T_{1}\right)$ energy level, and therefore becomes suitable for NIR lanthanide sensitization. In this mini-review, we summarize our recent progress to explore NIR lanthanide complexes for bioimaging and biolabeling. We firstly described the porpholactone chemistry to tailor the unsaturation degree and regioisomerism of the pyrrolic ring to profile the energy transfer efficiency from the triplet state of the ligand to the excited state of $\mathrm{Yb}^{3+}$. Then, we paid attention to remove the high energy vibration of $\mathrm{X}-\mathrm{H}(\mathrm{X}=\mathrm{C}, \mathrm{N}, \mathrm{O})$ oscillators, affording the NIR luminescent $\mathrm{Yb}^{3+}$ probes with exceptional brightness. Further proof-of-concept applications as optical tags for in vitro and in vivo NIR fluorescence imaging and fluorescence lifetime imaging demonstrated the prospects in NIR bioimaging and diagnosis. Finally, we discuss the remaining synthetic and practical challenges of NIR Ln molecular probes for future studies in lanthanide chemical biology and in vivo applications. $^{29}$ It is common in luminescent probes research to select "off-the-shelf" fluorophores for whatever application they are targeting, often selecting the moleuclar platforms or nanomaterials that "worked well for someone else". We hope that with this minireview we can help the researchers appreciate the many considerations in designing biological probes, learn how to evaluate which luminescent form may be suitable for their purposes, and highlight some recent discoveries in NIR Ln research that illustrate some of the key principles for original design of biological molecular probes.

\section{Design of the antenna porpholactone ligand: a prerequisite step to sensitize NIR lanthanides}

In contrast to visible emissive lanthanide(III) ions such as Eu (red), Tb (green), Sm (orange), and Dy (yellow) applied as biological probes, NIR luminescent Lns (Yb, Nd, Er, etc.) have 


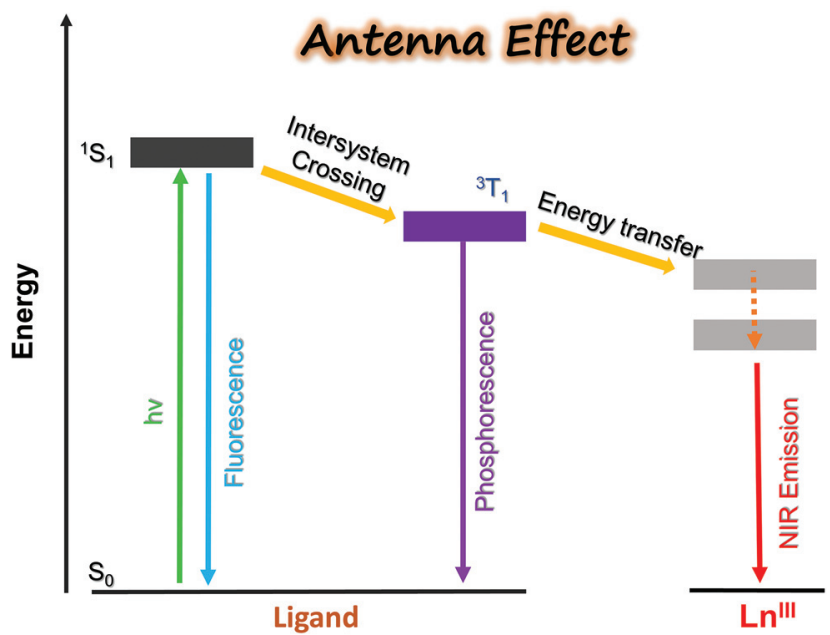

Fig. 1 Simplified Jablonski diagram for the antenna effect on lanthanide sensitization.

been much less reported due to their low quantum yields, although they are clinically favorable for their characteristic emission located in the biological transparent window. ${ }^{23}$ It is difficult to sensitize lanthanides through direct excitation from a high-intensity source, since the $\mathrm{Ln}^{3+} \mathrm{f}-\mathrm{f}$ electronic transition is forbidden and the molar absorption coefficient is small. Utilization of the "antenna effect", which means the energy transfer from the ligand triplet state to the upper levels of the lanthanide cation, provides a desirable alternative solution to circumvent the problem (Fig. 1). ${ }^{21}$ To achieve efficient energy transfer, the energy level of ligand $T_{1}$ should be higher than the excited state of the lanthanide. Besides, other quenching factors, including back energy transfer (BET), photo-induced electron transfer (PET), and multiphoton relaxation of $\mathrm{X}-\mathrm{H}$ oscillators ( $\mathrm{X}=\mathrm{C}, \mathrm{N}, \mathrm{O})$ should also be considered in the design of NIR lanthanide emitters.

So far, various organic ligands have been used for $\mathrm{Yb}^{3+}$ sensitization following the guidance of the Förster/Dexter energy transfer model and/or the energy-gap law. ${ }^{30}$ Porphyrinoid ligands, featured with large absorption coefficients, good coordination ability, tunable triplet energy states, and convenient chemical modification, have been employed as antenna ligands by many researchers with various auxiliary ligands (Fig. 2a). ${ }^{31}$

Among them, porpholactone, in which an oxazolone group replaces a pyrrole moiety in a porphyrin macrocycle, has attracted increasing attention since it was firstly reported thirty years ago. ${ }^{32}$ Our group reported the " $\mathrm{RuCl}_{3}+$ Oxone®" protocol for the concise synthesis of porpholactone on a gram scale, making it much easier to enrich the fascinating porpholactone library for further applications (Fig. 2b). ${ }^{33-35}$ These types of ligands feature synthetic flexibility by modification of $\pi$-porphyrinic periphery, which is effective for tuning the electronic structures including the ground and excited states, and the photophysical properties in the visible to NIR region. In recent years, we summarized our progress in the porpho-
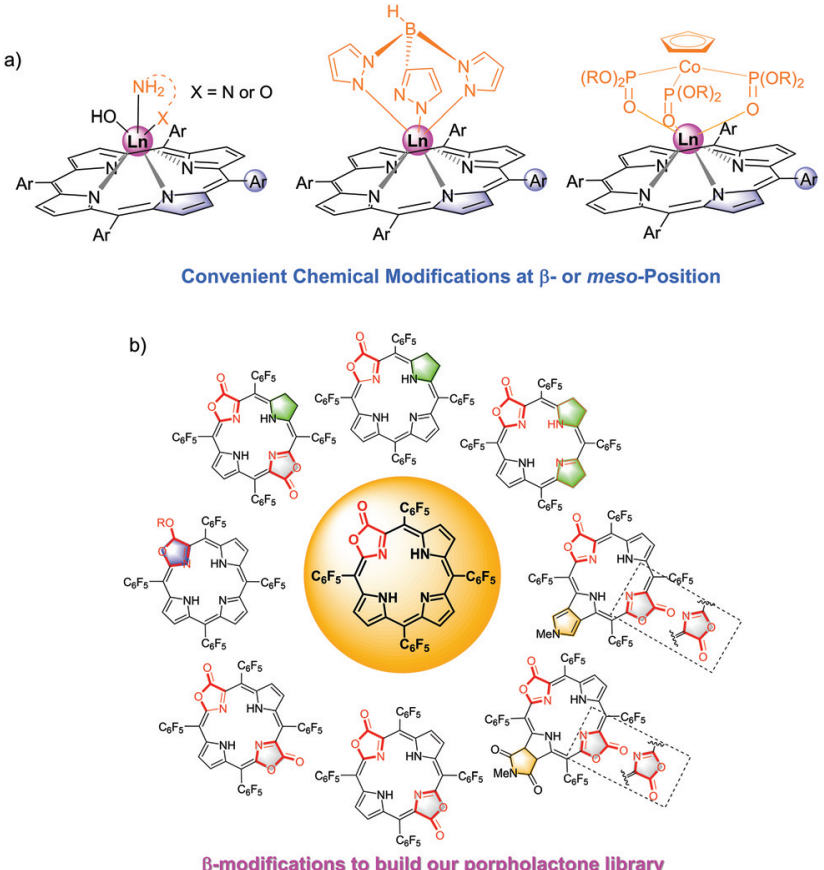

Fig. 2 (a) Typical lanthanide porphyrinate complexes. (b) Porpholactone library constructed by our group.

lactone library through tuning the saturation level of $\pi$-periphery and the orientation of $\beta$-dilactone moieties. ${ }^{36}$

Preliminary study showed that $\beta$-lactonization of the pyrrolic ring could remarkably enhance the $\mathrm{Yb}^{3+}$ NIR emission by $50 \%-120 \%$ and extend its lifetime by narrowing the energy gap between the triplet energy state of porphyrinoids and the emissive state of $\mathrm{Yb}^{3+}$ (Fig. 3a). ${ }^{37}$ Moreover, we demonstrated

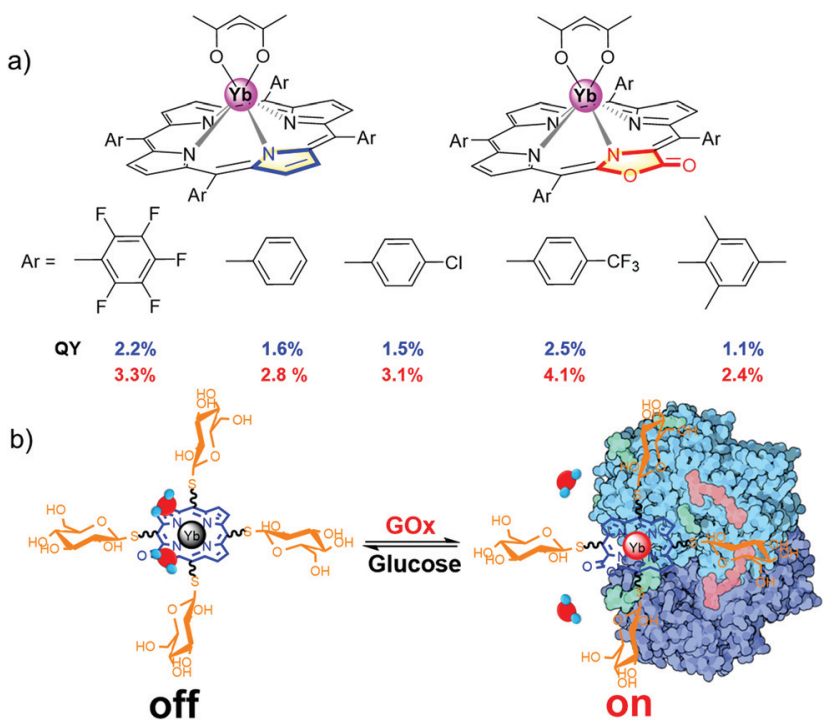

Fig. 3 (a) $\beta$-Lactonization of porphyrin to enhance the quantum yield of the $\mathrm{Yb}^{3+}$ cation. (b) Chemical structure of the water-soluble Yb porpholactone complex and its sensing for glucose oxidase. Reproduced with permission from ref. 37. Copyright 2014 Wiley-VCH. 
the potential applications of water-soluble $\mathrm{Yb}$ porpholactone to detect glucose by conjugating glucose to it. Interestingly, the NIR emission of this Yb bioprobe could be specifically switched on by glucose oxidase and then switched off in the presence of glucose, which is the first demonstration that nonpyrrolic porphyrin ligands enhance the QY of Ln luminescence (Fig. 3b). ${ }^{37}$ This encouraged us to systematically look into the intriguing porpholactone derivatives for NIR Ln sensitization.

\section{Design of NIR Yb complexes}

\subsection{Regioisomeric effect on the sensitization of Yb(III) NIR} emission

Naturally occurring chlorophyll b, d, and f with gradually redshifted $\mathrm{Q}$ bands have set us a golden standard to modulate the deep red absorption by altering $\beta$-formyl group orientation. ${ }^{38}$ Inspired by the natural approach, we used porphodilactone as a synthetic model, which enables fine-tuning of the lowest triplet excited states via subtle $\beta-\mathrm{C}=\mathrm{O}$ configurational isomerism (Fig. 4).$^{39,40}$ To investigate the bio-inspired orientation effect on NIR Yb sensitization, cis/trans porphodilactones were employed as antenna ligands to coordinate $\mathrm{Yb}^{3+}$ cations. ${ }^{41}$ Prominently, we found that the $\mathrm{Yb}^{3+}$ NIR emission could be switched "on/off" by the cis/trans porphodilactones with the quantum yields (QYs) of $3.32 \%$ and $0.41 \%$, respectively. The difference in QY is mainly due to the energy transfer efficiency from the lowest triplet excited state of the ligand $\left(\mathrm{T}_{1}\right)$ to the emissive level of $\mathrm{Yb}^{3+}\left({ }^{2} \mathrm{~F}_{5 / 2}, \mathrm{Yb}^{*}\right)$, as a result of $\beta$-substituent orientation alteration.

By estimating the energy level of the $\mathrm{T}_{1}$ state of cis/trans porphodilactones from the phosphorescence spectra of cis-GdLOMe and trans-Gd-LOMe at $77 \mathrm{~K}$, we found that the energy gap between the $\mathrm{T}_{1}$ state of cis-porphodilactone and the excited state of $\mathrm{Yb}^{*}\left(c a .1152 \mathrm{~cm}^{-1}\right)$ is much larger than that of the trans-isomer $\left(c a .-25 \mathrm{~cm}^{-1}\right)$. This larger energy gap gives rise to an energy transfer efficiency, according to the "energy gap law". In addition, to evaluate the effect of a subtle structural change, the spectral overlap between the phosphorescence of cis-Gd-LOMe or trans-Gd-LOMe and the f-f transition absorption of $\mathrm{Yb}^{3+}$ was also investigated. More spectral overlap was found in $\boldsymbol{c i s}$-Yb-LOMe, which is believed to facilitate the energy transfer process and thus NIR emission accord-

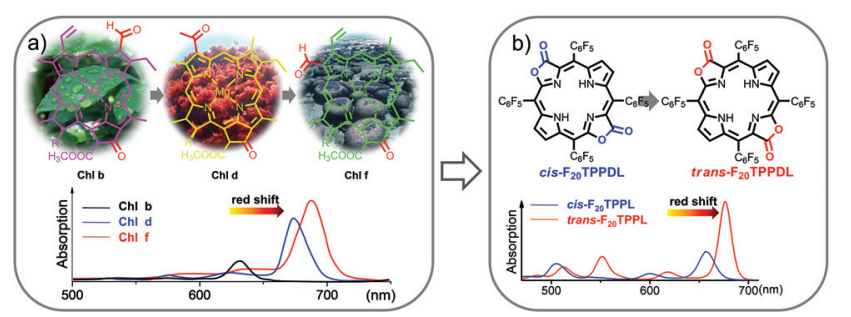

Fig. 4 ( $a$ and $b$ ) The bio-inspired orientation effect on tuning the porphyrinic $T_{1}$ energy state. Reproduced with permission from ref. 41. Copyright 2014 American Chemical Society.
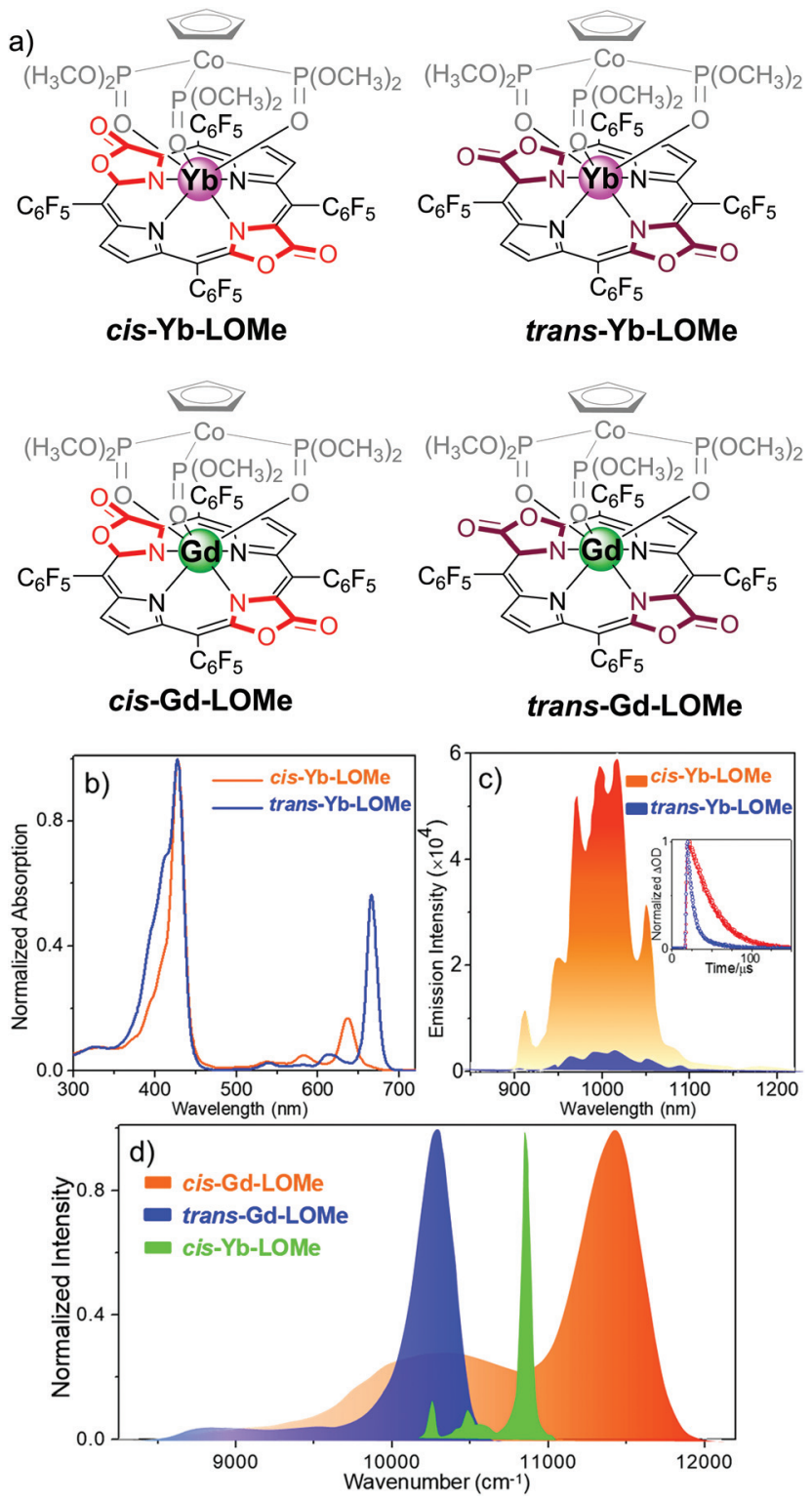

Fig. 5 (a) Chemical structure of cis-Ln-Lome and trans-Ln-Lome ( $\mathrm{Ln}=\mathrm{Yb}$ or Gd). (b) Normalized electronic absorption of cis-Yb-Lome and trans$\mathrm{Yb}$-Lome in DCM. (c) NIR luminescence spectra of cis-Yb-Lome and trans$\mathrm{Yb}$-LoMe in DCM at room temperature (inset: decay curve monitored at $970 \mathrm{~nm}$ ). (d) Normalized phosphorescence emission spectra of cis- and trans-Gd-Lome at $77 \mathrm{~K}$ in $\mathrm{CH}_{3} \mathrm{OH} / \mathrm{C}_{2} \mathrm{H}_{5} \mathrm{OH}(\mathrm{v} / \mathrm{v}=1: 1)$ and $\mathrm{f}-\mathrm{f}$ transitions ${ }^{2} \mathrm{~F}_{7 / 2} \rightarrow{ }^{2} \mathrm{~F}_{5 / 2}$ of $\mathrm{Yb}^{3+}$ in cis- $\mathrm{Yb}-\mathrm{L}_{\mathrm{OMe}}$ in $\mathrm{CD}_{2} \mathrm{Cl}_{2}$. Reproduced with permission from ref. 41. Copyright 2017 American Chemical Society.

ing to the energy transfer (either Förster or Dexter) mechanism (Fig. 5).

Sensitization efficiency is not the only factor to determine the quantum yield of $\mathrm{Yb}$ complexes. For example, $\beta$-lactonization can promote the energy transfer process between the porphyrinic ligand and the excited state of $\mathrm{Yb}$ by narrowing the energy gap $(\eta \sim 100 \%)$; however, the overall quantum yields (QYs) are still low $(<5 \%)$. According to eqn (1), overall quantum yields are determined by both high sensitization efficiency $(\eta)$ and large intrinsic quantum yield $\left(\phi_{\mathrm{Ln}}^{\mathrm{Ln}}\right)$. 
Thus, the method to achieve a high intrinsic quantum yield is another critical factor.

$$
\phi_{\mathrm{Ln}}^{\mathrm{L}}=\eta \times \phi_{\mathrm{Ln}}^{\mathrm{Ln}}=\eta \times \frac{\tau_{\mathrm{obs}}}{\tau_{\mathrm{rad}}}
$$

\section{2. $\beta$-Fluorination: an important approach to achieve a high intrinsic quantum yield}

High energy vibration of $\mathrm{X}-\mathrm{H}(\mathrm{X}=\mathrm{C}, \mathrm{N}, \mathrm{O})$ oscillators from the ligands and solvents are detrimental and can cause quenching of the excited state of $\mathrm{Yb}^{3+}$, which leads to a low intrinsic quantum yield. To remove or reduce detrimental $\mathrm{X}-\mathrm{H}$ oscillators in the vicinity of the Ln ion, halogenation and deuteration of ligands could be suitable choices. ${ }^{42}$ A variety of perfluorinated antenna ligands such as bis(perfluorooctylsulfonyl)amide, perdeuterated cryptand, bis(pentafluorophenyl) phosphinic acid and perfluorinated imidodiphosphinate have so far been applied to enhance NIR lanthanide emission especially by extending the lifetimes and intrinsic quantum yields. ${ }^{21}$ Nevertheless, their ligands have low absorption coefficients and high-lying triplet energy states, which are disadvantageous for the energy transfer process from the ligand to the Ln center. Hence the rational design of a porphyrinoid scaffold by diminishing $\mathrm{X}-\mathrm{H}(\mathrm{X}=\mathrm{C}, \mathrm{N}, \mathrm{O})$ oscillators is a promising approach to combine the suitable $\mathrm{T}_{1}$ energy levels for the $\mathrm{Yb}^{3+}$ excited state.

In 2017, we reported the combination of perfluorinated porphyrin $\left(\mathrm{F}_{28} \mathrm{TPP}\right)$ as the antenna ligand and deuterated Kläui's ligand $\left(\mathrm{NaL}_{\mathrm{OCD}}\right)$ as the ancillary ligand to significantly improve the QY of NIR Yb(III) emission. ${ }^{43}$ We could dramatically increase the overall quantum yield of the Yb-F $\mathbf{F}_{\mathbf{2 8}} \mathbf{T P P}-\mathbf{L}_{\mathbf{O C D} 3}$ complex up to the highest 63\% (estimated uncertainty 15\%), and extend the lifetime to $714 \mu \mathrm{s}$ in $\mathrm{CD}_{2} \mathrm{Cl}_{2}$ with an intrinsic quantum yield of $75 \%$ (Fig. 6). Given the splendid light-harvesting capability (extinction coefficient $\varepsilon \sim 320000 \mathrm{M}^{-1} \mathrm{~cm}^{-1}$ ) of the porphyrinoids,

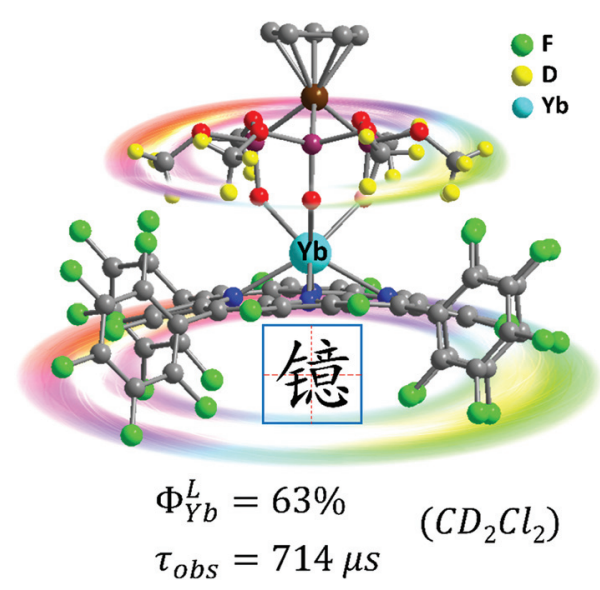

Fig. 6 Highly NIR-emissive ytterbium(III) complex Yb-F 28 TPP-LocD3 with a quantum yield of up to $63 \%$ in $\mathrm{CD}_{2} \mathrm{Cl}_{2}$ and a lifetime of up to $714 \mu$ s. Reproduced with permission from ref. 43. Copyright 2017 The Royal Society of Chemistry. this represents the brightest NIR emissive $\mathrm{Ln}^{3+}$ complexes (brightness: $\varepsilon \times \phi \sim 190000 \mathrm{M}^{-1} \mathrm{~cm}^{-1}$ ) ever reported, making it a fascinating fluorescent lanthanide probe for medical imaging and diagnosis in the NIR biological window.

In addition to the primary coordination sphere, tuning the secondary coordination sphere is also useful to enhance the NIR lanthanide luminescence but has been much less explored. In 2018, we investigated the sensitization ability of porpholactols with "up/down" isomers, after the reduction of porpholactones by DIBAL. ${ }^{44}$ For Yb-up, in which the $\beta$-hydroxyl group is at the same side of the $\mathrm{Yb}$ center, an intramolecular hydrogen bond with the axial Kläui's ligand was easily formed, while Yb-down could not, because the $\beta$-hydroxyl group below the porphyrin plane was far away from Kläui's ligand. X-ray diffraction (XRD) analysis suggested that the intramolecular hydrogen bond in Yb-up could shorten the distance between the emissive $\mathrm{Yb}^{3+}$ center and the $\beta-\mathrm{O}-\mathrm{H}$ bond, which promoted the adverse non-radiative deactivation of the excited state of the central ion. Thus, Yb-down displayed a much higher quantum yield and longer lifetime $(4.5 \%, 41 \mu \mathrm{s})$ than Yb-up $(2.4 \%, 20 \mu \mathrm{s})$ due to the weaker vibration quenching effect of the $\beta-\mathrm{O}-\mathrm{H}$ bond, demonstrating the role of the secondary coordination sphere on Yb NIR emission (Fig. 7). Interestingly, for high sensitivity of $\mathrm{O}-\mathrm{H}$ vibration toward temperature and viscosity, Yb-up/down isomers were found to have potential in NIR optical thermometers and viscosity probes. This opens
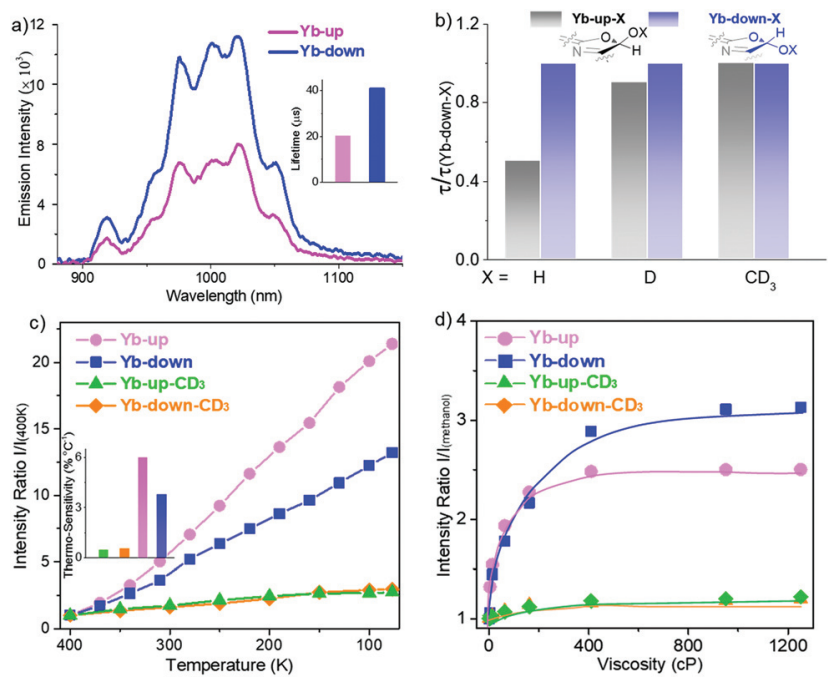

Fig. 7 Design of NIR luminescent $\mathrm{Yb}^{3+}$ probes sensitive to environmental stimuli through rationally tuning the secondary coordination sphere. (a) Comparison of NIR emission spectra between $\mathrm{Yb}$-up and $\mathrm{Yb}$ down ( $\left.\lambda_{\mathrm{ex}}=406 \mathrm{~nm}, A_{406 \mathrm{~nm}}=0.1\right)$. (b) Decay lifetime of $\mathrm{Yb}$-up-X with reference to $\mathrm{Yb}$ down- $\mathrm{X}\left(\mathrm{X}=\mathrm{H}, \mathrm{D}, \mathrm{CD}_{3}\right)$ monitored at $974 \mathrm{~nm}$ in $\mathrm{CH}_{2} \mathrm{Cl}_{2}$ at room temperature. (c) Emission intensity ratio normalized according to that at $400 \mathrm{~K}$ and thermosensitivity (inset) of $\mathrm{Yb}$-up (pink), $\mathrm{Yb}$-down (blue), $\mathrm{Yb}$ up- $\mathrm{CD}_{3}$ (green) and $\mathrm{Yb}$-down- $\mathrm{CD}_{3}$ (orange) in a PMMA thin film $(400-77 \mathrm{~K})\left(\lambda_{\mathrm{ex}}=406 \mathrm{~nm}, A_{406 \mathrm{~nm}}=0.1\right)$. (d) Emission intensity ratio normalized according to that in methanol of $\mathrm{Yb}$-up (pink), Yb-down (blue), $\mathrm{Yb}$-up- $C D_{3}$ (green) and $\mathrm{Yb}$-down- $C D_{3}$ (orange) in methanol/glycerol mixtures of different viscosities $\left(\lambda_{\mathrm{ex}}=406 \mathrm{~nm}, A_{406 \mathrm{~nm}}=0.1\right.$ ). Reproduced with permission from ref. 44. Copyright 2018 American Chemical Society. 
access to the design of NIR lanthanide functional materials sensitive to external or environmental stimuli.

\section{NIR lanthanide molecular probes for diagnosis and treatment}

\subsection{NIR lanthanide optical molecular tags}

For NIR emissive lanthanide ions, their unique spectral properties and negligible physical side effects undoubtedly make them promising and competitive labels among the whole clinically useful luminescent toolbox in terms of sensitivity, cost, and user-friendliness.

However, at present, NIR Lns such as $\mathrm{Yb}, \mathrm{Nd}$ and Er have been much less studied compared to visible Lns such as Eu and $\mathrm{Tb}$ in bioimaging and bioanalysis. For the development of NIR emissive Ln probes, several groups have contributed pioneering studies. Charbonnière, Seitz and others investigated on improving NIR lanthanide luminescence by extending lanthanides' radiative lifetime by minimizing the multiphonon relaxation of the harmful $\mathrm{X}-\mathrm{H}$ bond $(\mathrm{X}=\mathrm{C}, \mathrm{N}, \mathrm{O})$ and by optimizing the energy transfer process by finely tailoring the antenna ligands. ${ }^{4-48}$ Eliseeva, Petoud and coworkers prepared a polynuclear $\mathrm{Sm}^{3+}$ dendrimer for simultaneous visible and NIR cell imaging. Petoud and coworkers reported the sandwich lanthanide metallocrowns for necrotic cell imaging. ${ }^{24}$ Wong and co-workers reported a $\mathrm{Yb}^{3+}$ complex conjugated with rhodamine $\mathrm{B}$ for NIR-to-visible two photon live cell imaging. ${ }^{25}$ Borbas and his coworkers reported the first $\mathrm{Nd}$ chlorine complex based on a dipicolinic acid (dpa) framework, which can be excited by a Q band. ${ }^{49}$ Maury and co-workers prepared water-soluble $\mathrm{Yb}^{3+}$ complexes based on acetenyl functionalized triazacyclononane for two photon NIR-to-NIR bioimaging. ${ }^{26,50}$

However, all NIR Ln complexes mentioned above suffer from a quite low quantum yield, which calls for our further efforts on developing NIR luminescent Ln probes with both good quantum yield and biocompatibility. The recently reported perfluorinated sandwich porphyrin ytterbium complex $\mathbf{Y b}-\mathbf{F}_{28}$ TPP-L $\mathbf{L}_{\mathbf{O C D} 3}$ exhibits unprecedented NIR luminescence and stability, but perfluorination makes it too hydrophobic to be taken up by cells. ${ }^{51}$ Therefore, a biocompatible modification is necessary for the purpose of biological applications (Fig. 8). We firstly embedded the water-soluble functional groups such as glycosyl, carboxyl and triphenylphosphonium, respectively, onto the meso position of porphyrin to obtain water-soluble Yb-1-3. By reduction of the lactone moiety of porpholactones, we attached a hydrophilic quaternary ammonium group to the $\beta$-pyrrolic ring. Through $\beta$-1,3-dipolar cycloaddition, we could also improve its lipophilicity by attaching the ammonium group. When it comes to cell experiments, we noticed that $\mathbf{Y b}-\mathbf{5}$ showed an $\mathrm{IC}_{50}$ value as low as $1.0 \mu \mathrm{M}$ for HeLa cells, arising from the singlet oxygen generation induced phototoxicity, while Yb-1-4 exhibited negligible cytotoxicity even at $10 \mu \mathrm{M}$ concentration (cell viability $>80 \%$ ) under light radiation. Interestingly, upon excitation at $420 \mathrm{~nm}$, Yb-2-4 displayed intense intracellular NIR luminescence with preferential colocalization to lysosomes, but Yb-1 was NIR inert, which indicated the effect of biocompatible functionalities on the cellular uptake and intracellular localization.

Notably, we also used water-soluble $\mathrm{Yb}^{3+}$ molecular probes with a quantum yield of $c a .10 \%$ in water (Yb-6), which exhibited more than $3 \mathrm{~mm}$ penetration depth upon excitation at the Q band. Yb-6 was successfully applied in high resolution whole body, vasculature and lymph node imaging of small mice. This complex metabolized through hepatobiliary and renal systems, like most organic fluorophores. Importantly, we applied Yb-6 in fluorescence-guided sentinel lymph node surgery, which is the first application of NIR-II lanthanide molecular probes in surgical navigation on the mice model (Fig. 9). ${ }^{52}$

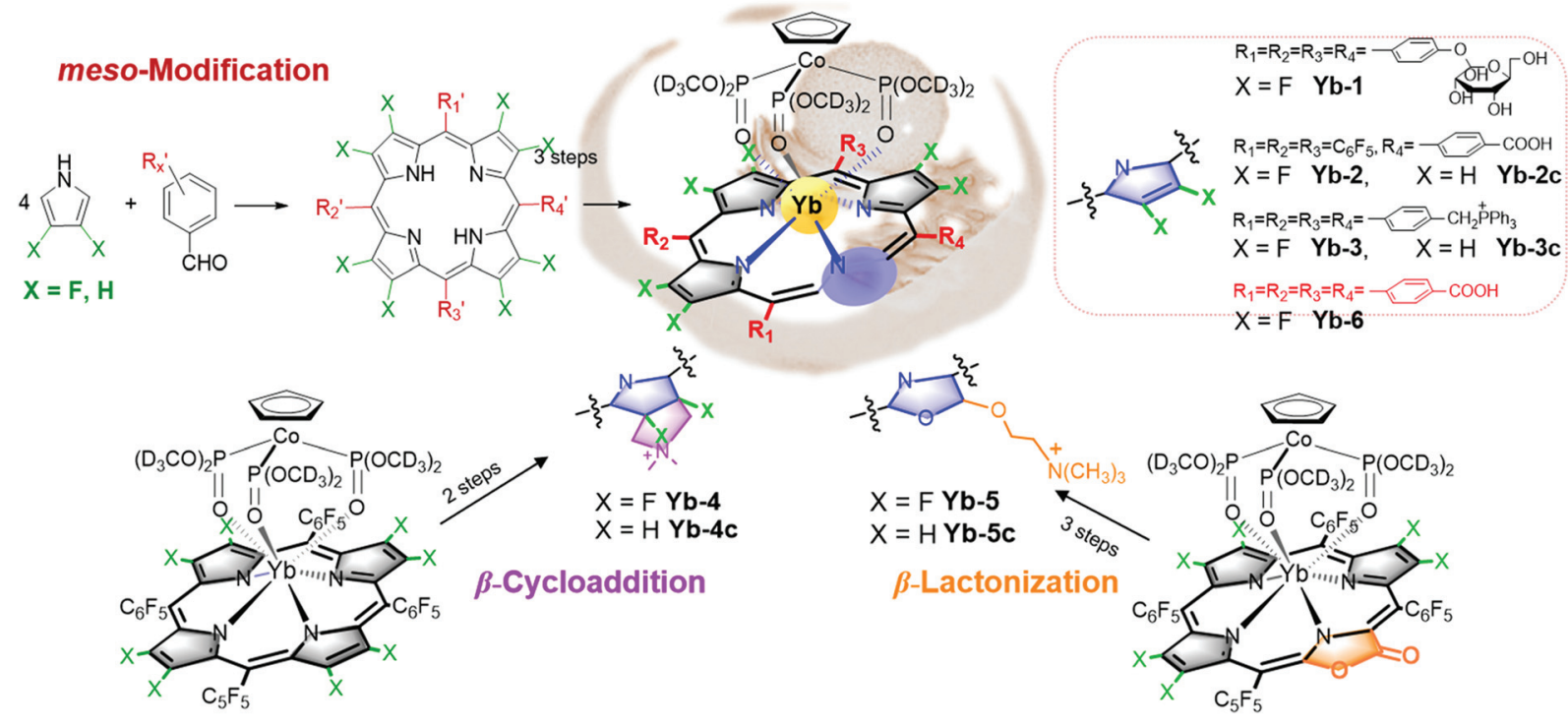

Fig. 8 Synthesis of biocompatible $\beta$-fluorinated $\mathrm{Yb}^{3+}$ complexes. 

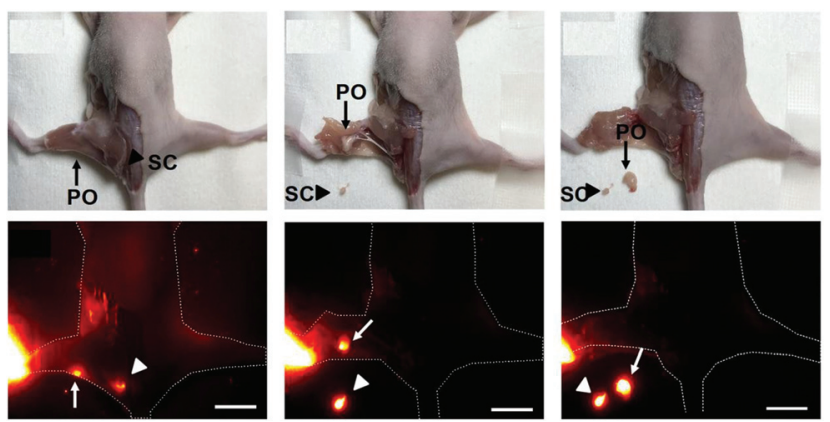

Fig. $9 \beta$-Fluorinated $\mathrm{Yb}^{3+}$ complexes were successfully applied in in vivo imaging and they help fluorescence-guided sentinel lymph node surgery. Reproduced with permission from ref. 52. Copyright 2019 The Royal Society of Chemistry.

Compared to the fluorescence intensity imaging, timeresolved fluorescence lifetime imaging (FLIM) does not rely on the local fluorophore concentration and enables quantitative visualization of the physiological environment fluctuation. Ln ions usually have a much longer lifetime $\left(10^{-6}-10^{-2} \mathrm{~s}\right)$ than biological autofluorescence, thus allowing their application as time-resolved imaging agents. In addition, lanthanide emission is hypersensitive to their coordination sphere, making real-time responsive imaging possible. When it comes to these biocompatible $\beta$-fluorinated $\mathrm{Yb}^{3+}$ porphyrinate compounds, they displayed very long decay lifetime on a $\mu$ s scale, making them ideal $\tau$-probes for FLIM. As shown in the in vitro FLIM experiment of $\mathbf{Y b - 4 / 4 \mathbf { c }}$ (Fig. 10), Yb-4 has a much higher lifetime between 100 and $200 \mu \mathrm{s}$ than that of Yb-4c $(20-40 \mu \mathrm{s})$. Interestingly, we found that the lifetime of $\mathbf{Y b}-\mathbf{4}$ varies with various subcellular organelles, which can be ascribed to intracellular microenvironment viscosity differences according to the experiments. ${ }^{51}$ This result greatly inspired us to pursue NIR lifetime $\tau$ probes from the $\beta$-fluorinated $\mathrm{Yb}^{3+}$ porphyrinic library with high stability, good irreversibility and sensitivity to microenvironment stimuli in vivo.

There are few reports of NIR Ln in vivo FLIM examples so far. In 2015, Thomas and coworkers reported NIR fluorescence lifetime imaging by loading the complexes of $\mathrm{Nd}^{3+}$ and $\mathrm{Yb}^{3+}$
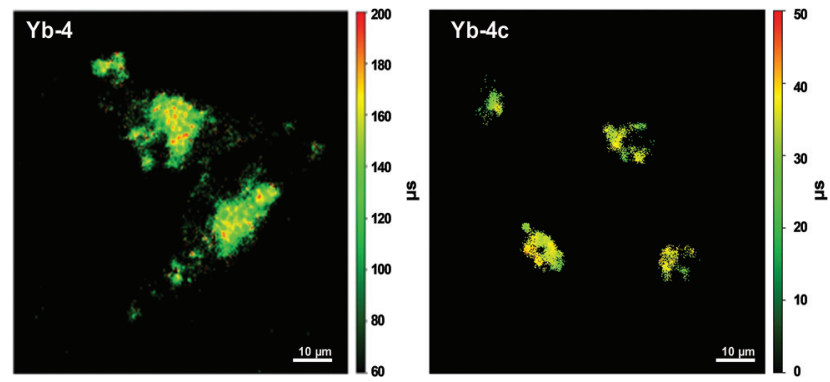

Fig. 10 NIR time-resolved image of live HeLa cells incubated with $10 \mu \mathrm{M}$ Yb-4 and $\mathrm{Yb}-4 \mathrm{c}\left(\lambda_{\mathrm{ex}}, 405 \mathrm{~nm}\right.$; $\lambda_{\mathrm{em}}$, long pass $850 \mathrm{~nm}$; dwell time, $20 \mathrm{~ms}$ ). Scale bar: $10 \mu \mathrm{m}$. Reproduced with permission from ref. 51. Copyright 2018 The Royal Society of Chemistry. into silicon nanoparticles. In 2017, Maury and coworkers

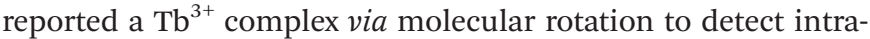
cellular viscosity but in the visible region. ${ }^{53}$ We recently reported one upper gastrointestinal $\mathrm{pH} \tau$-probe based on a brilliant NIR $\tau$-probe library. ${ }^{54}$ The upper gastrointestinal $\mathrm{pH}$ fluctuation reflects the relevant life metabolism behavior in the human body. Currently, an invasive endoscopy test is a traditional but rather painful method for clinical treatment to monitor gastrointestinal $\mathrm{pH}$ values. ${ }^{55}$ The wide range of $\mathrm{pH}$ values in the digestive tract is from 1 to 3 in the stomach to 6-7 in the intestine. In contrast, as a non-invasive method, FLIM can realize the real-time visualization of $\mathrm{pH}$ changes in the upper gastrointestinal tract safely, quickly and accurately. Based on the $\beta$-fluorinated $\mathrm{Yb}^{3+}$ molecular platform, we developed a NIR fluorescence lifetime $\tau$-probe Yb-6 by attaching four carboxylic groups at the meso position (Fig. 11). With this $\tau$-probe, the $\mathrm{pH}$ change is reflected through the difference in the NIR lifetime and intensity.

The Yb-6 was used to report the $\mathrm{PH}$ regulation capability of the antiacid drug hydrotalcite chewable tablets in the gastrointestinal tract. Compared with the fuzzy results of fluorescence intensity imaging upon ingestion of hydrotalcite, the fluorescence lifetime of $\mathrm{Yb}$ in the stomach showed a reversible change from $170 \mu \mathrm{s}$ to $130 \mu \mathrm{s}$ and then back to $170 \mu \mathrm{s}$, in accordance with the change of gastric $\mathrm{pH}$ from 1.5 to 6.5 to 1.5 (Fig. 12). Therefore, these results indicate that the NIR fluorescent $\tau$-probe can realize the real-time and reversible monitoring of gastrointestinal $\mathrm{pH}$ fluctuations, which reveals the prospects of the luminescent $\beta$-fluorinated $\mathrm{Yb}^{3+}$ porphyrinates in visualization of in vivo molecular events.

$\mathrm{Lu}^{3+}$ bears an $\mathrm{f}^{14}$ closed shell electronic structure and large spin-orbit coupling constants $\left(1153 \mathrm{~cm}^{-1}\right)$, which tends to promote the singlet-triplet intersystem crossing (ISC). ${ }^{56}$ Thus,
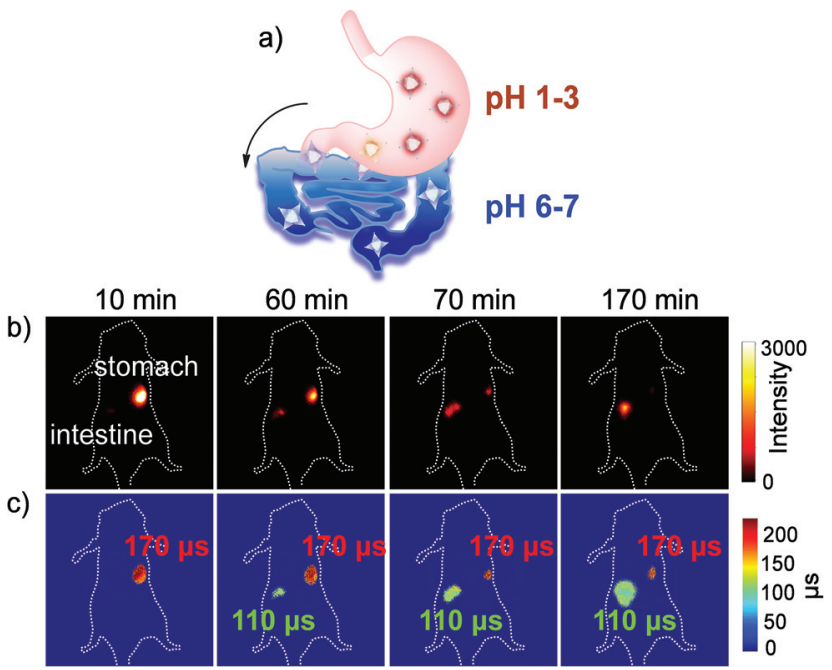

Fig. 11 (a) Schematic illustration of the metabolic process of Yb-6 from the stomach to the intestine. (b) NIR fluorescence intensity imaging (exposure time, $25 \mathrm{~ms}$ ) of the $\mathrm{Yb}^{3+}$ complex. (c) FLIM images (exposure time, $250 \mathrm{~ms}) . \lambda_{\mathrm{ex}}, 532 \mathrm{~nm} ; \lambda_{\mathrm{em}}, 1000 \mathrm{~nm}$ longpass. Reproduced with permission from ref. 54. Copyright 2019 The Royal Society of Chemistry. 
a) medicine
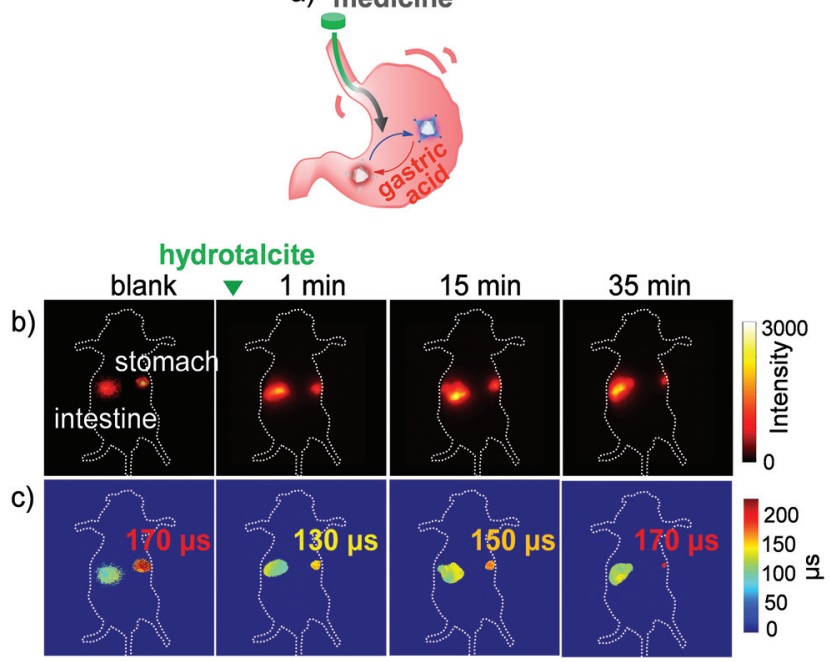

Fig. 12 (a) Schematic illustration of monitoring $\mathrm{pH}$ changes by $\mathrm{Yb}-6$ in the anti-acid process in the stomach. (b) NIR intensity fluorescence imaging (exposure time, $25 \mathrm{~ms}$ ). The green triangle at the top indicates the gavage of hydrotalcite. (c) FLIM images (exposure time, $250 \mathrm{~ms}$ ). $\lambda_{\text {ex, }}$ $532 \mathrm{~nm} ; \lambda_{\mathrm{em}}, 1000 \mathrm{~nm}$ long pass. Reproduced with permission from ref. 54. Copyright 2019 The Royal Society of Chemistry.

Lu porphyrinoid complexes are suitable for upconversion based on triplet-triplet annihilation (TTA-UC). Therefore, to enrich the lanthanide-based luminescent toolbox, we also tried to develop porpholactone $\mathrm{Lu}^{3+}$ porphyrinoid photosensitizers for TTA-UC imaging, which is the first attempt to employ lanthanide complexes as photosensitizers for TTA-UC (Fig. 13). ${ }^{57}$ Generally, TTA processes are bimolecular dynamic quenching processes and rely on diffusional interactions, thus longer triplet lifetimes of either sensitizers or acceptors benefit $\Phi_{\mathrm{UC}}$. This hypothesis is supported by the trend of the $\Phi_{\mathrm{UC}}$ of Lu-1-4, with the lifetime order of Lu-1 $>$ Lu-2 $>$ Lu-3 $\approx$ Lu-4. Importantly, we could enhance the $\Phi_{\mathrm{UC}}$ of Lu-1 and Lu-2 in aqueous solutions by encapsulating them to mesoporous silica nanoparticles (MSNs), respectively, which enables live cell imaging and provides a proof-of-concept example of TTA-UC of lanthanide complexes for further biolabelling in in vivo lanthanide chemical biology.

\section{2. $\mathrm{Gd}^{\mathrm{III}}$ porpholactone complexes for the rational design of theranostic agents}

Theranostics is an emerging medical treatment, which incorporates both therapeutic and diagnostic agents within the same scaffold and paves a way for personalized medicine design. Based on our previous research, we have reported a series of chlorine-type photosensitizers with different $\beta$-ionic terminal groups such as glycosyl, sulfonic and zwitterionic groups and carefully investigated their cellular PDT activities. ${ }^{58}$ A theranostic agent with photodynamic therapy (PDT) and magnetic resonance imaging (MRI) modalities is really promising for pre-treatment planning, therapy monitoring and treatment outcome assessment, so further research on Ln porphyri-

a)
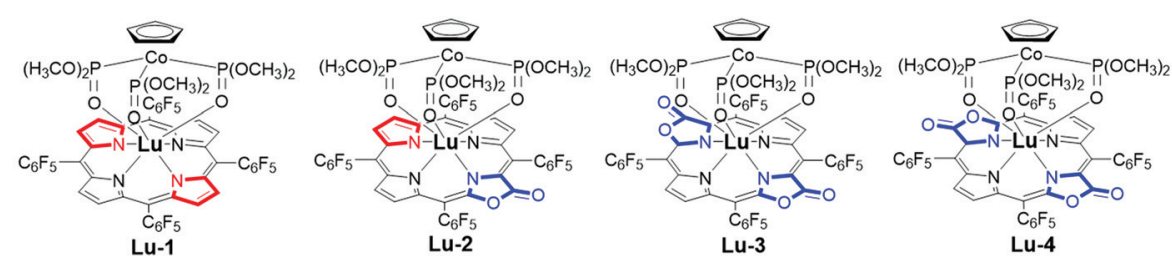

b)

$$
\begin{aligned}
& \text { 1) } \mathrm{CTAB} ; \mathrm{NaOH} ; \mathrm{H}_{2} \mathrm{O} \\
& \mathrm{Si}(\mathrm{OEt})_{4} \\
& \frac{80^{\circ} \mathrm{C}, 2 \mathrm{~h}}{\text { 2) conc. } \mathrm{HCl} ; \mathrm{MeOH}} \\
& \text { rf., } 24 \mathrm{~h}
\end{aligned}
$$

c)
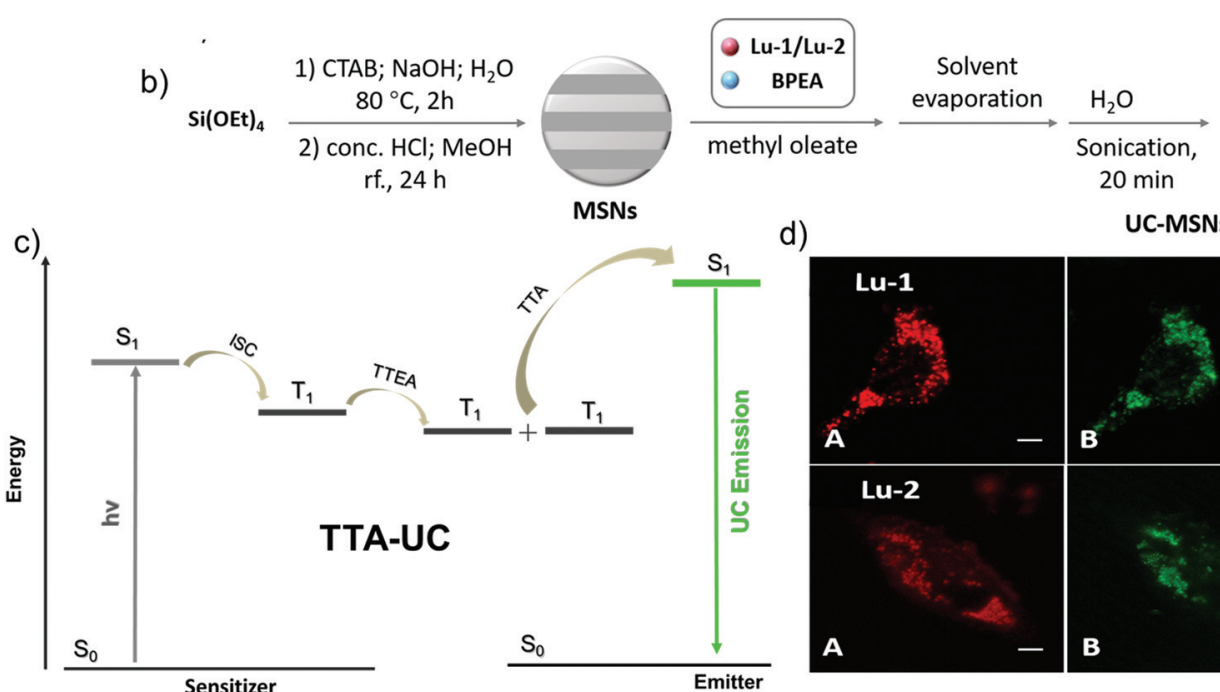

d)
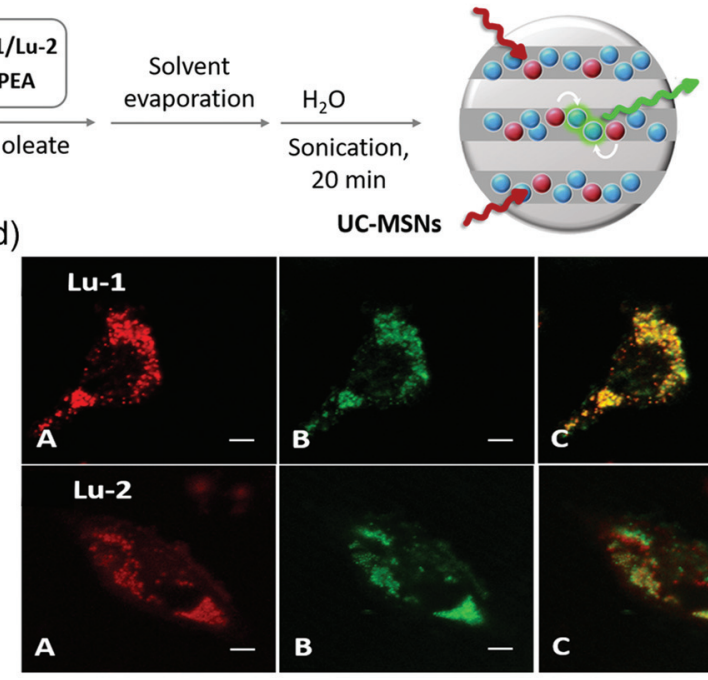

UC-MSNs

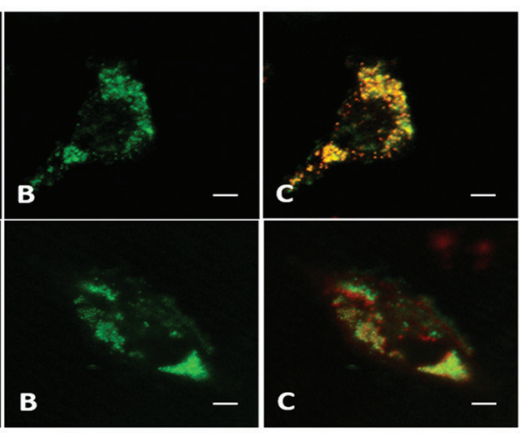

Fig. 13 (a) Chemical structures of Lu-1-4. (b) Illustration of the preparation scheme of UC-MSNs. (c) Scheme for TTA-UC via conventional triplet sensitization routes. (d) Confocal fluorescence images of living HeLa cells. Reproduced with permission from ref. 57 . Copyright 2018 The Royal Society of Chemistry. 


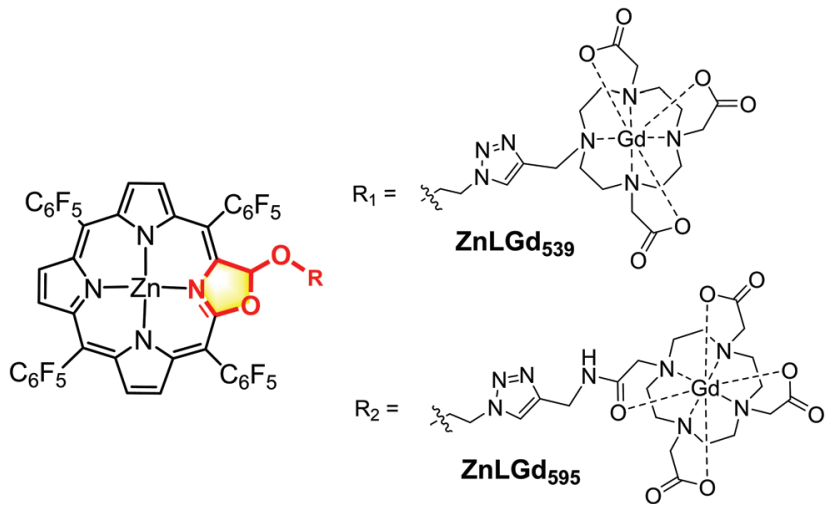

Fig. 14 Chemical strategy to entitle the MRI modality to the Zn-porpholactol framework. noids is important. ${ }^{59}$ Based on our porpholactone library, we selected the phototoxic zinc(II) porpholactol as the mother skeleton for PDT functionality, and then introduced $\beta$-conjugation of the Gd $^{\text {III }}$ DOTA complex for the MRI modality (Fig. 14). ${ }^{60}$ To our delight, they showed largely enhanced $r_{1}$ relaxivities compared with that of clinically used MRI contrast agents like GdDOTA and GdDTPA (DOTA = 1,4,7,10-tetraazacyclododecane-1,4,7,10-tetraacetate, DTPA = diethylenetriamine pentaacetate), and very good photocytotoxicity towards HeLa cells $\left(\mathrm{IC}_{50}<2 \mu \mathrm{M}\right)$, making them promising candidates for non-invasive theranostic agents with PDT and MRI dual modalities.

Importantly, to develop new theranostic agents, it is obviously more attractive to combine diagnostic and therapeutic modalities within a single $\mathrm{Gd}^{\mathrm{III}}$ molecule entity compared with tedious chemical modifications of commercial MRI contrast agents. The $\mathrm{Gd}^{3+}$ ion has a high-lying $\mathrm{f}-\mathrm{f}$ transition, so Gd complexes display the population of the $\mathrm{T}_{1}$ state of

a)

Wong's Work:

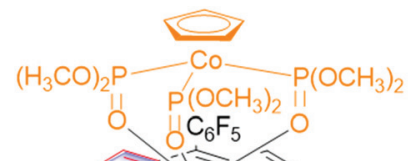

b)

C) 1

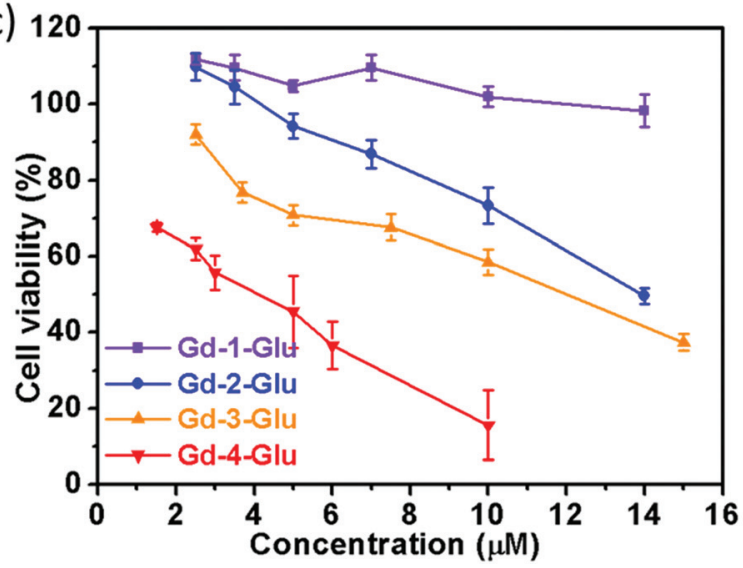

d)
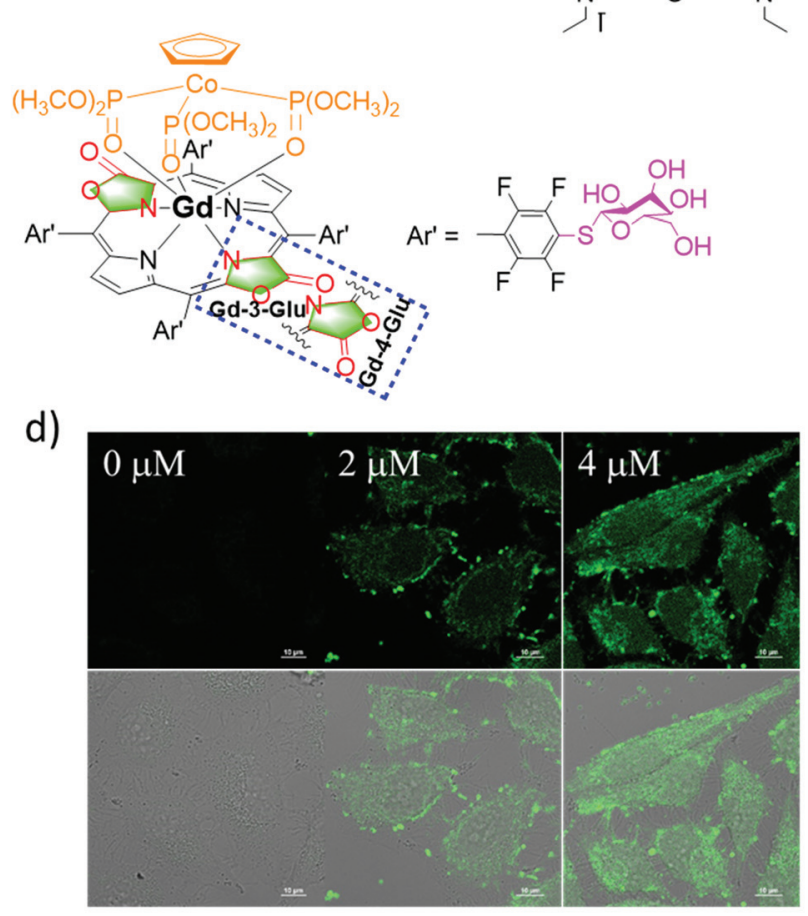

Fig. 15 (a) Chemical structure of Wong's work on the design of Gd theranostic agents. (b) Chemical structure of our work on the design of Gd theranostic agents. (c) Photocytotoxicity of Gd-1-4-Glu toward HeLa cells by using a CCK-8 assay under different wavelengths of light irradiation at $600-700 \mathrm{~nm}$ with the same dose of light $(6.5 \mathrm{~mW} \mathrm{~cm}$ ) for $30 \mathrm{~min}$, and then cultured in the dark for another $24 \mathrm{~h}$. (d) H2DCFDA fluorescence images of HeLa cells under different drug doses of Gd-2-Glu; 0-2 $\mu \mathrm{M}$ Gd-2-Glu in the dark for $24 \mathrm{~h}, 10 \mu \mathrm{M}$ H2DCFDA for 30 min, then irradiated with visible light $\left(400-700 \mathrm{~nm}, 6.5 \mathrm{~mW} \mathrm{~cm}^{-2}\right)$ for $30 \mathrm{~min}$. Reproduced with permission from ref. 62. Copyright $2016 \mathrm{Wiley-VCH}$. 
ligands which are oxygen sensitive. ${ }^{59}$ In the meantime, the Gd complexes are good candidates for MRI due to their unique magnetic properties arising from the seven unpaired $4 \mathrm{f}$ electrons. In 2014, Wong and co-workers reported two Gd complexes with combined PDT and MRI modalities, which can specifically kill HeLa cells via ${ }^{1} \mathrm{O}_{2}$ generation under irradiation but their biocompatibility and ${ }^{1} \mathrm{O}_{2}$ quantum yield still need to be improved (Fig. 15). ${ }^{61}$ This remarkable research work inspired our design of next generation dual modal Gd theranostic agents with combined PDT and MRI functionalities. In 2016, we synthesized a series of gadolinium(III) porpholactone complexes and attempted to employ them as dual model theranostic agents with PDT and MRI functionalities (Fig. 15). ${ }^{62}$ We found that as the porphyrinic ligand triplet state energy level decreased in the order of Gd-1 $<$ Gd-2 $<$ Gd-3 $<$ Gd-4, the gradually narrowed energy gaps could facilitate the energy transfer process from the ligand lowest triplet state to the ${ }^{1} \Delta_{\mathrm{g}}$ state of ${ }^{1} \mathrm{O}_{2}$, which significantly facilitates the singlet oxygen $\left({ }^{1} \mathrm{O}_{2}\right)$ quantum yield up to 0.99 . After glycosidation modifications, Gd-4-Glu became water-soluble and more photocytotoxicity $\left(\mathrm{IC}_{50}=4.1 \mu \mathrm{M}\right)$ was observed than that of the other Gd1-3-Glu toward HeLa cells in the intracellular PDT experiments, which is highly correlated to the perfect photoinduced ${ }^{1} \mathrm{O}_{2}$ sensitization capability of Gd-4. For MRI activity, Gd-4-Glu also exhibited increased $r_{1}$ relaxivity due to the number and orientation differences of the $\beta$-lactone moieties in the pyrrolic ring, which also revealed the superiority of our porpholactone framework. Notably, in vivo MRI guided PDT experiments on tumor mice models of Gd-1-4-Glu are also being currently studied in our group.

\section{Conclusion and outlook}

In this mini-review, we summarize the progress in bioinspired porphyrinoid based lanthanide complexes and their applications in bioimaging and biolabelling, and further the attempt to develop theranostic reagents. These results suggest the importance of Ln coordination compounds as NIR imaging molecular probes especially in combination with the merits of organic dyes and metal nanoparticles. In spite of the progress made in the last 5 years, more concerns should be taken into consideration due to the growing importance of lanthanide cations in life science.

One is the stability of Ln complexes both in aqueous media and/or upon light irradiation. Biocompatibility is another issue. The current NIR Ln molecular probes are not designed for specific biological targets or events and may not accurately image biological events of interest. To improve their targeting ability, development of bioconjugation with peptides, proteins, and anti-bodies is a desirable strategy. A Ln bioconjugate usually should consist of three parts: the Ln label, which is comprised of a cation and some antenna ligands, an activated functional group that shows high reactivity with targets, and the linker between the Ln complexes and the bioactive moiety. The third challenge is that the excitation wavelength for the
NIR lanthanide still needs to be red-shifted to the biological window (700-1000 nm), namely "NIR to NIR". Despite some pioneering studies revealing the fact that two-photon absorption can facilitate the design of NIR-NIR Ln complexes, the strategy is still limited. Better ligand design is critical to prepare NIR $\mathrm{Ln}^{3+}$ complexes with a broad scope, such as $\mathrm{Nd}^{3+}$, $\mathrm{Er}^{3+}, \mathrm{Ho}^{3+}$ and $\mathrm{Tm}^{3+}$, which are rare earth elements that have not been exploited much. Finally, we are also looking forward to more researchers joining the journey to NIR Ln molecular probes and enrich the $\mathrm{Ln}^{3+}$ optical toolbox, thus facilitating further development of lanthanide chemical biology and achieving their medicinal applications in the future.

\section{Conflicts of interest}

There are no conflicts to declare.

\section{Acknowledgements}

We thank the National Scientific Foundation of China (NSFC) (21571007, 21621061, 21778002, and 21861162008) and the National Key Basic Research Support Foundation of China (NKBRSFC) (2015CB856301) for financial support. This work was also supported by the High-performance Computing Platform of Peking University.

\section{Notes and references}

1 G. Hong, A. L. Antaris and H. Dai, Nat. Biomed. Eng., 2017, $1,1$.

2 I. Martinić, S. V. Eliseeva and S. Petoud, J. Lumin., 2017, 189, 19.

3 S. He, J. Song, J. Qu and Z. Cheng, Chem. Soc. Rev., 2018, 47, 4258.

4 Kenry, Y. Duan and B. Liu, Adv. Mater., 2018, 30, 1802394.

5 C. Li and Q. Wang, ACS Nano, 2018, 12, 9654.

6 H. Wan, H. Du, F. Wang and H. Dai, Adv. Funct. Mater., 2019, 1900566, DOI: 10.1002/adfm.201900566.

7 J. Xu, A. Gulzar, P. Yang, H. Bi, D. Yang, S. Gai, F. He, J. Lin, B. Xing and D. Jin, Coord. Chem. Rev., 2019, 381, 104.

8 Y. Fan and F. Zhang, Adv. Opt. Mater., 2019, 7, 1801417.

9 H. Wang, X. Mu, J. Yang, Y. Liang, X.-D. Zhang and D. Ming, Coord. Chem. Rev., 2019, 380, 550.

10 Q. Miao and K. Pu, Adv. Mater., 2018, 30, 1801778.

11 Y. Liu, V. Gunda, X. Zhu, X. Xu, J. Wu, D. Askhatova, O. C. Farokhzad, S. Parangi and J. Shi, Proc. Natl. Acad. Sci. U. S. A., 2016, 113, 7750.

12 I. Medintz, H. T. Uyeda, E. Goldman and H. Mattoussi, Nat. Mater., 2005, 4, 435.

13 G. Hong, S. Diao, A. L. Antaris and H. Dai, Chem. Rev., 2015, 115, 10816. 
14 H. Dong, S. R. Du, X. Y. Zheng, G. M. Lyu, L. D. Sun, L. D. Li, P. Z. Zhang, C. Zhang and C. H. Yan, Chem. Rev., 2015, 115, 107255.

15 F. Ding, Y. Zhan, X. Lu and Y. Sun, Chem. Sci., 2018, 9, 4370-4380.

16 F. Ding, Y. Fan, Y. Sun and F. Zhang, Adv. Healthcare Mater., 2019, 8, e1900260.

17 C. P. Montgomery, B. S. Murray, E. J. New, R. Pal and D. Parker, Acc. Chem. Res., 2009, 42, 925.

18 S. V. Eliseeva and J. C. Bunzli, Chem. Soc. Rev., 2010, 39, 189.

19 J.-C. G. Bünzli, Chem. Rev., 2010, 110, 2729.

20 Y. Ning, M. Zhu and J.-L. Zhang, Coord. Chem. Rev., 2019, 399, 213028.

21 J.-C. G. Bünzli, Coord. Chem. Rev., 2015, 293-294, 19.

22 M. Sy, A. Nonat, N. Hildebrandt and L. J. Charbonnière, Chem. Commun., 2016, 52, 5080.

23 E. Mathieu, A. Sipos, E. Demeyere, D. Phipps, D. Sakaveli and K. E. Borbas, Chem. Commun., 2018, 54, 10021.

24 A. Foucault-Collet, C. M. Shade, I. Nazarenko, S. Petoud and S. V. Eliseeva, Angew. Chem., Int. Ed., 2014, 53, 2927.

25 T. Zhang, X. Zhu, C. C. Cheng, W. M. Kwok, H. L. Tam, J. Hao, D. W. Kwong, W. K. Wong and K. L. Wong, J. Am. Chem. Soc., 2011, 133, 20120.

26 A. D’Aléo, A. Bourdolle, S. Brustlein, T. Fauquier, A. Grichine, A. Duperray, P. L. Baldeck, C. Andraud, S. Brasselet and O. Maury, Angew. Chem., Int. Ed., 2012, 51, 6622.

27 C. Anthony and L. J. Zatman, Biochem. J., 1964, 92, 614.

28 D. E. Barry, D. F. Caffrey and T. Gunnlaugsson, Chem. Soc. Rev., 2016, 45, 3244.

29 L. J. Daumann, Angew. Chem., Int. Ed., 2019, 58, 12795.

30 R. Englman and J. Jortner, Mol. Phys., 1970, 18, 145.

31 H. He, Coord. Chem. Rev., 2014, 273, 87.

32 M. J. Crossley, J. Chem. Soc., Chem. Commun., 1984, 920.

33 Y. Yu, H. Lv, X. Ke, B. Yang and J.-L. Zhang, Adv. Synth. Catal., 2012, 354, 3509.

34 J.-Y. Hu, Z.-Y. Wu, K. Chai, Z.-S. Yang, Y.-S. Meng, Y. Ning, J. Zhang and J.-L. Zhang, Inorg. Chem. Front., 2017, 4, 1539.

35 Y. Yao, Y. Rao, Y. Liu, L. Jiang, J. Xiong, Y. J. Fan, Z. Shen, J. L. Sessler and J. L. Zhang, Phys. Chem. Chem. Phys., 2019, 21, 10152.

36 Y. Ning, G. Q. Jin and J. L. Zhang, Acc. Chem. Res., 2019, 52, 2620.

37 X. S. Ke, B. Y. Yang, X. Cheng, S. L. Chan and J. L. Zhang, Chem. - Eur. J., 2014, 20, 4324.

38 M. Chen, Annu. Rev. Biochem., 2014, 83, 317.

39 X. S. Ke, Y. Chang, J. Z. Chen, J. Tian, J. Mack, X. Cheng, Z. Shen and J. L. Zhang, J. Am. Chem. Soc., 2014, 136, 9598.
40 X. S. Ke, H. Zhao, X. Zou, Y. Ning, X. Cheng, H. Su and J. L. Zhang, J. Am. Chem. Soc., 2015, 137, 10745.

41 Y. Ning, X. S. Ke, J. Y. Hu, Y. W. Liu, F. Ma, H. L. Sun and J. L. Zhang, Inorg. Chem., 2017, 56, 1897-1905.

42 E. Kreidt, C. Kruck and M. Seitz, Handb. Phys. Chem. Rare Earths, 2018, 53, 35.

43 J. Y. Hu, Y. Ning, Y. S. Meng, J. Zhang, Z. Y. Wu, S. Gao and J. L. Zhang, Chem. Sci., 2017, 8, 2702.

44 Y. Ning, Y. W. Liu, Y. S. Meng and J. L. Zhang, Inorg. Chem., 2018, 57, 1332.

45 N. Souri, P. Tian, C. Platas-Iglesias, K. L. Wong, A. Nonat and L. J. Charbonnière, J. Am. Chem. Soc., 2017, 139, 1456.

46 A. Nonat, S. Bahamyirou, A. Lecointre, F. Przybilla, Y. Mely, C. Platas-Iglesias, F. Camerel, O. Jeannin and L. J. Charbonnière, J. Am. Chem. Soc., 2019, 141, 1568.

47 J. W. Caroline Bischof, J. Scholten, S. Trosien and M. Seitz, J. Am. Chem. Soc., 2010, 132, 14334.

48 C. Doffek and M. Seitz, Angew. Chem., Int. Ed., 2015, 54, 9719.

49 R. Xiong, D. Mara, J. Liu, R. Van Deun and K. E. Borbas, J. Am. Chem. Soc., 2018, 140, 10975-10979.

50 A. T. Bui, M. Beyler, A. Grichine, A. Duperray, J. C. Mulatier, Y. Guyot, C. Andraud, R. Tripier, S. Brasselet and O. Maury, Chem. Commun., 2017, 53, 6005.

51 Y. Ning, J. Tang, Y. W. Liu, J. Jing, Y. Sun and J. L. Zhang, Chem. Sci., 2018, 9, 3742.

52 Y. Ning, S. Chen, H. Chen, J.-X. Wang, S. He, Y.-W. Liu, Z. Cheng and J.-L. Zhang, Inorg. Chem. Front., 2019, 6, 1962.

53 A. T. Bui, A. Grichine, A. Duperray, P. Lidon, F. Riobe, C. Andraud and O. Maury, J. Am. Chem. Soc., 2017, 139, 7693.

54 Y. Ning, S. Cheng, J. X. Wang, Y. W. Liu, W. Feng, F. Li and J. L. Zhang, Chem. Sci., 2019, 10, 4227.

55 H. Du, M. Liu, X. Yang and G. Zhai, Drug Discovery Today, 2015, 20, 1004.

56 M. Montalti, A. Credi, L. Prodi and M. T. Gandolfi, Handb. Photochem., 2006, 353.

57 Z.-S. Yang, Y. Ning, H.-Y. Yin and J.-L. Zhang, Inorg. Chem. Front., 2018, 5, 2291.

58 X.-S. Ke, J. Tang, J.-J. Chen, Z.-Y. Zhou and J.-L. Zhang, ChemPlusChem, 2015, 80, 237.

59 S. Jenni and A. Sour, Inorganics, 2019, 7, 10.

60 X.-S. Ke, J. Tang, Z.-S. Yang and J.-L. Zhang, J. Porphyrins Phthalocyanines, 2014, 18, 950.

61 T. Zhang, R. Lan, C. F. Chan, G. L. Law, W. K. Wong and K. L. Wong, Proc. Natl. Acad. Sci. U. S. A., 2014, 111, E5492.

62 X. S. Ke, Y. Ning, J. Tang, J. Y. Hu, H. Y. Yin, G. X. Wang, Z. S. Yang, J. Jie, K. Liu, Z. S. Meng, Z. Zhang, H. Su, C. Shu and J. L. Zhang, Chem. - Eur. J., 2016, 22, 9676. 